\title{
TRABALHO E DESENVOLVIMENTO SOCIAL: PROPOSTA DE UMA NOVA REGULAMENTAÇÃO PARA O BOLSA FAMÍLIA A PARTIR DO RECONHECIMENTO DO TRABALHO COMO VALOR SOCIAL

\author{
TRABAJO Y DESARROLLO SOCIAL: PROPUESTA DE UNA NUEVA \\ REGULACIÓN PARA EL BOLSA FAMILIA A PARTIR DEL RECONOCIMIENTO \\ DEL TRABAJO COMO VALOR SOCIAL
}

\author{
Renata Teixeira Villarim ${ }^{1}$ \\ Flavia De Paiva Medeiros De Oliveira ${ }^{2}$
}

\section{RESUMO}

Este trabalho apresenta uma análise sobre a pobreza e a exclusão social, a fim de identificar suas implicações na configuração de políticas públicas no Brasil, fazendo um estudo do Programa Bolsa Família. O seu objetivo é avaliar se tal Programa cumpriu a sua finalidade e sobre a possibilidade de inclusão de uma nova condicionalidade, que é a relativa ao trabalho e empreendedorismo, como forma de garantir uma real inserção social dos seus beneficiários.

Palavras-chave: Inclusão social, Bolsa família, Valor social do trabalho, Empreendedorismo, Desenvolvimento social

\begin{abstract}
Este trabajo presenta un análisis sobre la pobreza y la exclusión social, para identificar sus implicaciones en la configuración de las políticas públicas en Brasil, haciendo un estudio del Programa Bolsa Familia. Su objetivo es evaluar se tal Programa cumplió su finalidad e sobre la posibilidad de inclusión de una nueva condicionalidad, que dice respeto al trabajo, como forma de garantizar una real inserción social de sus beneficiarios.
\end{abstract}

Keywords: Inclusión social, Bolsa familia, valor social del trabajo, Capacidad de emprender, Desarrollo social

\footnotetext{
${ }^{1}$ Mestranda em Direito e Desenvolvimento Sociopolítico Sustentável pelo Centro Universitário de João Pessoa UNIPÊ, Paraíba, (Brasil). E-mail: renata@advocaciagrm.com

2 Doutorada em Direito do Trabalho e Previdência Social pela Universitat de València, Valência, (Espanha). Professora pela Universidade Estadual da Paraíba - UEPB e pelo Centro Universitário de João Pessoa - UNIPÊ, Paraíba, (Brasil). E-mail: flaviadepaiva@ hotmail.com
} 


\section{CONSIDERAÇÕES INICIAIS}

O presente artigo tem como objetivo analisar o Programa Bolsa Família, que figurou como uma das tentativas mais efetivas de implantar uma política pública de acesso aos direitos sociais.

Para lograr esse cometido analisaremos a bibliografia produzida sobre o tema durante os últimos anos.

A exclusão social tem sido, no Brasil, veementemente, associada à questão da restrição de renda, à carência de recursos financeiros, à falta de assistência de uma maneira geral sendo a mesma, um grande óbice ao desenvolvimento.

Vislumbra-se que a pobreza generalizada atrelada às guerras civis, à exclusão sócio econômica, além dos massacres, fome, e outras mazelas do mundo contemporâneo, tornaramse assuntos preocupantes, principalmente nos chamados países emergentes.

As desigualdades sociais e econômicas existentes no Brasil atingem níveis cada vez mais alarmantes, trazendo consequências graves à própria sobrevivência de uma parcela significativa da população. Elas se expandem cada vez mais pelos grandes centros, através do desemprego generalizado e contínuo, mal das grandes metrópoles, assim como ausência de perspectiva das classes menos favorecidas, e da violência que assola o país.

Diante da necessidade de distribuir renda, como um dos fatores que pode levar ao desenvolvimento econômico, muitos questionamentos podem ser levantados, tendo em conta a situação das pessoas beneficiárias do Programa Bolsa Família. A proposta é analisar se o referido Programa é capaz de permitir um mínimo existencial às famílias pobres ou extremamente pobres, como um meio para a construção de uma sociedade que não seja desigual e com maiores condições de quebrar o histórico ciclo de marginalização do Brasil. 


\section{EXCLUSÃO SOCIALIINCLUSÃO SOCIAL}

A exclusão social como realidade de fato se inscreve na história das desigualdades, não sendo um fenômeno novo. No entanto, os avanços científicos, tecnológicos e todos os processos de desenvolvimento econômico das últimas décadas, proporcionaram a uma grande parcela da população mundial maiores níveis de bem estar, ainda que geraram ou deixaram um sem número de pessoas sem acesso às condições desse bem estar. Esses avanços e as modificações na sociedade capitalista redesenharam as desigualdades que agora não tem mais exclusivamente a lógica das sociedades de classe, mas ameaça provocar um esgarçamento do próprio tecido social.

O termo exclusão/inclusão social, nos últimos anos, passou a fazer parte tanto das agendas políticas que se propõem ao resgate dos direitos fundamentais de uma parcela da população, como do vocabulário social cotidiano para designar uma série de condições que, de maneira geral, poderiam ser caracterizadas como o desrespeito à igualdade por um lado e como desrespeito à diferença por outro ou ainda como a negação dos direitos de cidadania. A inclusão social, por sua vez, estaria caracterizada por condições diametralmente opostas às anteriormente referidas. Em nosso cotidiano, observa-se que, comumente, se equipara a exclusão com marginalidade considerada tanto em uma perspectiva, digamos, de território, na condição de estar fora de algo, como em uma dimensão pejorativa e carregada de conotação moral. Mais comum ainda é que a exclusão esteja vinculada à noção de pobreza.

Atribui-se a René Lenoir a origem mais contemporânea do termo exclusão social ao publicar em 1974 o livro, Les exclus: un français sur dix ('Os excluídos: um em cada dez franceses'), ainda que o trabalho não contivesse qualquer elaboração teórica do conceito de exclusão social (ESCOREL, 2009).

Robert Castel, sociólogo francês que ocupou durante algum tempo a Direção de Estudo da Ècole des Hautes Études en Sciences Sociales em Paris, em um artigo sobre a Dinâmica dos processos de marginalização, embora reconhecendo que na base dos processos de marginalização existe a situação de miséria econômica, considera difícil estabelecer patamares de pobreza que sirvam como critérios definidores de marginalidade (ele não fala até aqui de exclusão) e, portanto dos indivíduos que necessitam de auxílio. Castel fala da existência de uma "pobreza integrada" como aquela existente nas sociedades europeias anteriores ao século XIX. Essa pobreza integrada estava constituída por pessoas que, embora vivendo em condições de 
precariedade econômica e de desprovimento de bens, quase no limite do humano, por terem determinadas atividades produtivas eram consideradas autônomas e não dependiam de auxílios sociais. "No entanto, outros grupos, como vagabundos, que a priori não eram nem mais nem menos "pobres", recebiam um tratamento totalmente diferente e eram completamente marginalizados”. (CASTEL, 1997, p. 21).

Castel diz que a marginalização aparece no final de um duplo processo de desligamento: do trabalho e das relações interpessoais. Nesse processo de integração/degradação existiriam três zonas. A zona de integração onde o indivíduo teria um trabalho estável e uma inserção relacional também forte; a zona de vulnerabilidade onde existiria a precarização do trabalho e falhariam os apoios relacionais e finalmente uma zona que ele chamou de zona de "desfiliação" onde o indivíduo não teria trabalho nem contaria com os apoios interpessoais. Uma quarta zona foi definida por Castel ao se referir à "indigência inválida", da qual fazem parte os que não podem trabalhar e que por essa razão recebe os apoios sociais... (CASTEL, 1997, p. 24).

Embora o termo "exclusão", segundo o autor, tenha sido muito utilizado na década de 70 do século passado, para caracterizar a situação de não integração social, considerava-se uma condição de exceção ou ainda "arcaísmos dos progressos da modernidade". "Podia-se aceitar ou se indignar com estes fenômenos, mas eles não colocavam em questão a dinâmica social geral". (CASTEL, 1997, p. 30).

Nessa perspectiva a exclusão social era algo que fugia à regra, algo que não fazia parte da essência de uma determinada forma de sociedade e que, como tal, deveria e poderia ser facilmente corrigida.

Castel considera que o termo "exclusão social" sinaliza fenômenos dispares, multidimensionais, se constituindo em uma categoria difusa. Nessa perspectiva são excluídas aquelas pessoas maduras, com bom nível de capacitação laboral, há muito tempo sem trabalho da mesma forma que é excluído o jovem pouco escolarizado, sem capacitação e que nunca teve um trabalho. Para ele, essa indiferenciação acaba por não ajudar a compreensão sobre suas origens e formas de aparecimento. 
Partindo das transformações do mercado de trabalho, o sociólogo francês Serge Paugan chamou de "desqualificação social" as situações de vida degradadas ou precarizadas e aponta para a chamada "nova pobreza". O estudo da desqualificação social significa para Paugan: (...) estudar a diversidade dos status que definem as identidades pessoais, ou seja, os sentimentos subjetivos acerca da própria situação que esses indivíduos experimentam no decorrer de diversas experiências sociais, e, enfim, as relações sociais que mantêm entre si e com o outro (PAUGAM, 2003 apud PIZZIO; VERONESE, 2008).

Pizzio e Veronese (2008) apostilam que segundo a tese de Paugan, no conceito de desqualificação social se integram três ideias que estão igualmente articuladas com o conceito de exclusão social: a noção de trajetória que se refere ao percurso temporal dos indivíduos; o conceito de identidade, positiva ou negativa, de crise e de construção dessa identidade e, por fim, o aspecto da territorialidade, ou seja, a base espacial que abriga processos excludentes. Por outro lado, Paugan considera a desqualificação um processo que supõe três fases ou momentos: a fragilidade, a dependência e a ruptura. A fragilidade está relacionada à experiência vivida do deslocamento social. São dificuldades laborais que levam à perda de referências, por exemplo, mudanças de local de moradia.

A dependência é a fase em que os serviços sociais responsabilizam-se pelas dificuldades enfrentadas pelos indivíduos. Essa dependência muitas vezes leva a que os indivíduos, desistam de ter um emprego. A ruptura é a fase da desqualificação social onde os indivíduos constroem uma identidade de marginalizados.

\section{A ASSISTÊNCIA SOCIAL NA CONSTITUIÇÃO DE 1988}

A Constituição de 1988 tratou da assistência social, tendo como ponto de partida a consideração do indivíduo como detentor de direitos, com a criação do Sistema de Seguridade Social e o reconhecimento legal da Assistência Social como política pública.

De acordo com essa perspectiva nova a assistência social é prestada a quem dela necessitar, independentemente de contribuição e tem como objetivos a proteção à família, à maternidade, à infância, à adolescência e à velhice; o amparo às crianças e adolescentes carentes; a promoção da integração ao mercado de trabalho; a habilitação e reabilitação das pessoas portadoras de deficiência e a promoção de sua integração à vida comunitária; a garantia 
de um salário mínimo mensal ao portador de deficiência e ao idoso que comprovem não possuir meios de prover a própria manutenção ou de tê-la provida por sua família na forma da lei. (Art. 203 da CF/1988).

A assistência social foi assentada como uma das três instituições políticas fundamentais da seguridade social, junto à saúde e à previdência social. Na década de 1990 três eventos, de certa forma, se articularam para construir um espaço de discussão e ação contra a desigualdade extrema existente no Brasil: a 'redescoberta' da fome; a emergência do movimento Ação da Cidadania Contra a Miséria e pela Vida (AÇÃO DA CIDADANIA, 1993), inspirado e conduzido de forma emblemática pelo sociólogo Herbert de Souza, o Betinho; e a adoção, pelo então presidente Itamar Franco, do Plano de Combate à Fome e à Miséria (CASTRO; MODESTO, 2010).

O objetivo do movimento Ação da Cidadania Contra a Fome, a Miséria e pela Vida foi mobilizar o país para a necessidade de transformar a realidade econômica que determinava a existência de excluídos miseráveis e famintos. Tratava-se de um movimento suprapartidário, ecumênico e plural. O Instituto de Pesquisa econômica Aplicada IPEA, realizou um estudo intitulado Mapa da Fome que deu visibilidade às condições devida da população. Foram criados Comités de Combate à fome com a participação de representantes dos mais variado setores da sociedade e que funcionavam em nível local, municipal ou estadual. Para realizar a coordenação Geral do Movimento foi criada a Comissão Executiva Nacional da Ação da Cidadania integradas por representantes da OAB, da Central Única dos Trabalhadores, pela Conferencia Nacional dos Bispos do Brasil, o Conselho Federal de economia, o Instituto Brasileiro de Análises Sociais e econômicas, a Instituto de Estudos Socioeconômicos (Inesc); e Associação Nacional de Dirigentes de Instituições Federais de Ensino Superior (Andifes) o que testemunha a importância do movimento.

Em 1995, no inicio do Governo de Fernando Henrique Cardoso foram adotadas outras medidas voltadas ao combate à pobreza, como o Programa Comunidade Solidária e a Rede de Proteção Social (...) uma junção de vários programas sociais, com prevalência dos programas de transferência de renda voltados ao atendimento à população de baixa renda (MOBILIZADORES COEP, 2014). 
Em 1996 foi criado o primeiro programa de Erradicação do Trabalho Infantil (PET) que transferia recursos monetários às famílias de baixa renda que mantivessem seus filhos menores de 16 anos na escola.

A Emenda Constitucional 31 de 2000 criou o Fundo de Combate e erradicação da Pobreza com o objetivo de que todos os brasileiros tivessem níveis dignos de subsistência. Durante dois anos o fundo contou com 0,02\% da Contribuição Provisória sobre Movimentações Financeiras (CPMF). Outras receitas previstas pela Constituição para alcançar esses objetivos são 5\% no Imposto sobre Produtos Industrializados incidente sobre produtos supérfluos e toda a arrecadação do Imposto sobre grandes fortunas (que ainda não existe).

Em 2001, durante o segundo mandato do Presidente Fernando Henrique Cardoso foram adotados programas de transferência de renda para famílias pobres, e precisamente em 2004, o Ministério do Desenvolvimento Social e Combate à fome-MDS foi criado com a finalidade da conjugação de esforços das políticas públicas nas áreas de assistência social, garantia nutricional e alimentar, saúde, educação infantil e ainda, transferência de renda. Nesse mesmo ano foi criado o Programa Nacional de Alimentação Escolar.

\section{BOLSA FAMÍlia: TENTATIVA DE INCLUSÃO SOCIAL E RESGATE DA CIDADANIA}

O conceito de pobreza é pluridimensional e o empenho em reduzir as desigualdades sociais acaba se relacionando aos conceitos de pobreza, indo além da questão econômica. Sen (2012) em seus trabalhos e sua medida geral da "linha de pobreza", distingue o que seja pobreza absoluta e pobreza relativa. Para ele a pobreza absoluta é aquela que expressa a não satisfação de um conjunto das necessidades básicas, incluído no pacote do que se postula como "mínimo vital". A pobreza relativa é definida por comparação de uma população que alcançou um patamar mínimo de sobrevivência com outra que dispõe de uma maior renda e bem estar.

Mas Sen (2012), observa que a pobreza pode ser definida como uma privação das capacidades básicas de um indivíduo e não apenas como uma renda inferior a um patamar pré-estabelecido. Pode-se afirmar, no entanto, que é necessário um "mínimo vital” para a população, onde os medidores oficiais de pobreza circulam e informam a questão da fome 
endêmica, do analfabetismo, ou, aliás, do baixo nível de escolaridade da população e a falta de moradia popular. Isso determinou que os governos tentassem, em "curto prazo" garantir a oferta de um mínimo das necessidades básicas da população.

O fato é que, por muito tempo, por décadas e décadas, a desigualdade e a pobreza têm caminhado juntas no Brasil, como resultado de modelos de crescimento que não promovem a inclusão e políticas sociais pouco eficazes.

Hodiernamente, a pobreza deve ser assim encarada:

\begin{abstract}
“Assim, a partir do século XX, a pobreza passou a ser analisada em razão da carência, da ausência de meios de subsistência, da escassez ou da desvantagem material. Pobreza, assim, passou a ser sinônimo de privação, baixa renda, miséria, exclusão e indigência." (SALES, 2016, p. 4).
\end{abstract}

A pobreza ou a extrema pobreza gera exclusão e representa um atentado contra o direito à vida e viola a dignidade da pessoahumana18. Impede o exercício das liberdades, conforme já explanado, e a participação democrática e consciente do cidadão. Desse modo, conforme já exposto, o critério monetário para auferir quem é pobre não é o mais indicado, tendo em vista que não considera outros elementos fundamentais, como as suas necessidades e peculiaridades e a garantia de direitos básicos como a democracia, a liberdade e igualdade.

Coerentemente, Sen (2012) observa, ainda, que a igualdade de oportunidades passa pela recuperação de capacidades, sendo a pobreza a carência de realização de capacidades elementares.

Nesse novo contexto de avaliação das liberdades, em 1996, foi criado o Programa de Erradicação de Trabalho Infantil ${ }^{3}$ cuja população alvo era crianças entre 7 a 15 anos. Tratavase do Primeiro Programa de Transferência de Renda Condicionada (PTRC) posto que exigia uma contrapartida de seus beneficiários. Nesse caso, a família recebia uma bolsa por criança que não trabalhasse em atividades (...) insalubres, perigosas ou degradantes, tais como o cultivo de cana ou carvoarias. (IPEA, 2010).

Em 2001 foi criado outro programa de transferência de renda condicionada que foi o Bolsa Escola Federal. Para recebê-la a família deveria garantir uma frequência à escola de $85 \%$ das aulas e uma renda familiar máxima de $\mathrm{R} \$ 90,00$ por pessoa. 
Também em 2001 foi criado o bolsa alimentação que exigia exames pré-natais, aleitamento materno e carteira de vacinação em dia.

O grande problema desses programas é que cada um deles tinha uma agencia executora e não havia uma coordenação central. O resultado disso é que muitas famílias recebiam vários benefícios em detrimento de outras.

Para unificar esses programas, o Governo Federal criou o Programa Bolsa Família em outubro de 2003 através da Medida Provisória 132/2003, posteriormente convertida na Lei n 10.836/2004, e regulamentado pelo Decreto 5.209/2004. Como se pode observar esse Programa foi o resultado de uma longa trajetória de política sociais instituídos por vários governos.

Trata-se de um programa de transferência de renda condicionada (PTRC) que exige uma contrapartida dos beneficiários na forma de manutenção dos seus filhos na escola, diferentemente dos Programas de Garantia de Renda Mínima cujo único critério era a renda. O Art. $3^{\circ}$ da Lei 10. 836/2004 prescreve que:

"A concessão dos benefícios dependerá do cumprimento, no que couber, de condicionalidades relativas ao exame pré-natal, ao acompanhamento nutricional, ao acompanhamento de saúde, à frequência escolar de $85 \%$ (oitenta e cinco por cento) em estabelecimento de ensino regular, sem prejuízo de outras previstas em regulamento." (BRASIL, 2004, p. 18).

A base de informações para concessão do beneficio é o Cadastro Único e cabe a Secretaria Nacional de Renda de Cidadania (SENARC), do Ministério do Desenvolvimento Social e Combate à Fome (MDS), estabelecer normas para sua execução.

Ao contrário da aposentadoria ou do seguro desemprego, por exemplo, o Bolsa Família não é um Direito. O paragrafo único do artigo sexto da Lei 10.836 estabelece: "O Poder Executivo deverá compatibilizar a quantidade de beneficiários do Programa Bolsa Família com as dotações orçamentárias existentes”.

\footnotetext{
3“'Sobre as políticas públicas assistenciais no país, destaca-se que as primeiras discussões sobre políticas de inclusão social ocorreram na década de 1970, com a criação da chamada previdência rural, entretanto, foi somente a partir de 1991 que houve a apresentação do Projeto de Lei $\mathrm{n}^{\circ}$ 2.561, criado pelo senador Eduardo Suplicy, para efetivar política nesse sentido. O projeto objetivava a criação de um imposto negativo, que beneficiaria pessoas acima de 25 anos que possuíam renda inferior a um determinado patamar, que, à época, correspondia a 2,5 salários mínimos. Ocorre que o projeto, apesar de ter sido aprovado perante o Senado, não foi objeto de votação pela Câmara dos Deputados, portanto, nunca entrou em vigor ." (SALES, 2016, p. 9).
} 
Esgotadas as disponibilidades orçamentárias o programa somente poderá continuar dando os benefícios se houver uma suplementação orçamentária.

O objetivo do Programa é "contribuir para a superação da pobreza no Brasil por meio de três frentes de atuação: a transferência direta de renda, que representa uma melhoria imediata nas condições de vida das famílias pobres; o acompanhamento das condicionalidades, como reforço do direito de acesso das famílias aos serviços básicos de saúde, educação e assistência social contribuindo para romper o ciclo de pobreza entre gerações e a oferta de programas complementares, que abrem oportunidades de desenvolvimento das famílias beneficiarias (Brasil 2011, p. 137) ${ }^{4}$.

Schimidt e Ribeiro (2015, p. 160) explica o seguinte sobre as condicionalidades do Programa referido:

"Sua sistemática de funcionamento divide-se em três eixos principais: a) a transferência direta de renda, para promover o alívio imediato das situações mais crônicas de fome; b) as condicionalidades para a permanência no programa, contrapartidas prestadas pelos beneficiários pela benesse recebida, também com o intuito de reforçar o acesso a direitos sociais básicos nas áreas de educação, saúde e assistência social; c) as ações e programas complementares que objetivam o desenvolvimento das famílias, de modo que os beneficiários consigam superar a situação de vulnerabilidade."

O Decreto regulamentador do Programa disciplina a quem caberá o acompanhamento das condicionalidades, ficando claro que os itens relativos à saúde e educação são acompanhados e fiscalizados pelos Ministérios de Saúde e de Educação enquanto que ao Ministério do Desenvolvimento Social e Combate à fome caberá o acompanhamento das demais condicionalidades.

A operacionalização da gestão dessas condicionalidades supõe uma rede organizacional complexa com a participação das três esferas administrativas - União, Estados e Municípios. A articulação das ações de gestão das condicionalidades em nível nacional é de responsabilidade do Departamento de Condicionalidades do Ministério de Desenvolvimento

\footnotetext{
${ }^{4}$ É o que diz o Art. $4^{\circ}$ do Decreto 5209 que regulamenta a Lei 10.836 : “ Os objetivos básicos do Programa Bolsa Família, em relação aos seus beneficiários, sem prejuízo de outros que venham a ser fixados pelo Ministério do Desenvolvimento Social e Combate à Fome, são: I - promover o acesso à rede de serviços públicos, em especial, de saúde, educação e assistência social; II - combater a fome e promover a segurança alimentar e nutricional; III - estimular a emancipação sustentada das famílias que vivem em situação de pobreza e extrema pobreza; IV - combater a pobreza; e V - promover a intersetorialidade, a complementaridade e a sinergia das ações sociais do Poder Público.
} 
Social e de Combate à fome.

\section{A NECESSIDADE DE REFORMULAR O BOLSA FAMÍliA A PARTIR DO TRABALHO COMO VALOR SOCIAL: UMA NOVA PROPOSTA DE REGULAÇÃO}

Analisando o contexto de sua criação, o Programa Bolsa Família encontra tem como razão ontológica promover a redução da pobreza e da desigualdade, promover a inclusão nas políticas públicas de educação e saúde, reduzir a insegurança alimentar, e fortalecer a trajetória escolar e a saúde de crianças e adolescentes, aumentando o compromisso destas políticas com as parcelas mais pobres da população brasileira (CAMPELLO, 2013, p. 19). Todavia, a real redução da pobreza e da desigualdade não exige apenas que se garanta uma renda mínima. É necessário que as famílias pobres ou extremamente pobres possam sair dessa condição e ter um mínimo de autonomia econômica capaz poderem, elas próprias, garantir a sua subsistência em condições dignas.

É imperioso analisar o programa mencionado à luz do valor social do trabalho. Isso porque, o trabalho figura, juntamente, com a dignidade como um dos princípios fundamentais da República Federativa do Brasil, no texto do art. 1º, III e IV, da Constituição vigente, o que significa que não pode haver dignidade sem trabalho. Embora a transferência de renda mínima à população pobre ou extremamente pobre tenha sido um mecanismo eficaz para tirar o Brasil da zona da fome, não é capaz de garantir o desenvolvimento social pleno dos beneficiários e de suas famílias, porque o próprio Programa não garante às famílias beneficiadas instrumentos capazes de fazer com que os beneficiários efetivamente possam mudar a sua condição social.

As condições ou contrapartidas do Programa estão limitadas às áreas da saúde, educação e assistência social; que objetivam possibilitar acesso e inserção da população pobre nos serviços sociais básicos, e ao mesmo tempo, favorecer a interrupção do ciclo de reprodução da pobreza. Deveriam estar previstas entre tais condicionalidades a possibilidade de desenvolvimento social e laboral dos responsáveis pelas famílias, a fim de que, durante o lapso temporal de recebimento do benefício, tais chefes de famílias se submetessem a uma capacitação laborativa com vistas a que pudessem, com seu próprio trabalho, alcançar melhores condições sociais e de desenvolvimento. 
Tais condicionalidades se destinam a envolver as famílias num circuito virtuoso de direitos e deveres com vistas a fomentar a cultura cívica e garantir o acesso a uma rede extensa de proteção social, sem, contudo, garantir a real emancipação dos beneficiários, que ocorre, sobretudo, com inclusão social real capaz de garantir o acesso ao mercado de trabalho (MONNERAT et al, 2007, p. 1456). Tratar-se-ia da inserção no Programa de mais uma condicionalidade, qual seja, a de empregabilidade e empreendedorismo (SCHMIDT; RIBEIRO, 2015, p. 165), cuja finalidade seria a de incentivar os membros das famílias beneficiadas que contam com mais de 18 (dezoito) anos a buscar a sua autonomia econômica.

Claro que, a atribuição dessa nova perspectiva demandaria uma articulação do Governo, através de programas complementares ${ }^{5}$ que seriam implementados pelos gestores locais, com a sociedade civil e as entidades do terceiro setor, o que, além de favorecer os próprios beneficiários, engajaria a sociedade, atribuindo ao Programa maior legitimação social ${ }^{6}$, já que todos estariam envolvidos na solução de um dos maiores problemas sociais do Brasil, que é a redução das desigualdades sociais e econômicas.

Essa nova proposta para o Programa Bolsa Família dimana do reconhecimento que a própria Constituição brasileira dá ao trabalho, atribuindo-lhe a natureza jurídica de valor social, no texto do art. 170, caput e art. 193. Sob o prisma da ordem econômica, o trabalho figura como um instrumento produtor de riquezas, que se expressa através da relação de emprego e de trabalho, por meio das quais ao correspondente dispêndio de força laborativa deve equivaler uma retribuição, que funciona como um dos eixos que viabilizam o desenvolvimento econômico da nação (RODRIGUES, 2003, p. 12).

\footnotetext{
5 Alguns programas governamentais que já existem podem auxiliar na concretização de uma nova condicionalidade como a proposta, como é o caso, por exemplo, do "Programa Brasil Alfabetizado"; "ProJovem"; "Projeto de Promoção do Desenvolvimento Local e Economia Solidária"; "Programa Nacional da Agricultura Familiar"; "Programas de Microcrédito do Banco do Nordeste"; "Programa Luz para Todos".

${ }^{6}$ Nesse sentido, Schmidt; Ribeiro (2015, p. 166-167) relatam o caso da parceria do SEBRAE com o Programa Bolsa Família, através do projeto daquele órgão, intitulado "Negócio a Negocio", por meio do qual se oferece, de forma gratuita, atendimento e orientação empresarial que oferece diagnósticos e recomendações para microempreendedores individuais e donos de microempresas.

A ideia é auxiliar nas principais dificuldades encontradas no dia-a-dia da gestão dos negócios, dos itens mais básicos (como, por exemplo, legalizar a situação de uma MEI), e mesmo para tirar dúvidas e planejamento estratégico. Por meio do programa, um Agente de Orientação Empresarial realiza visitas in loco na empresa do beneficiário ou realiza reunião na sede do SEBRAE, local para iniciar os procedimentos de criação de uma pessoa jurídica.
} 
Sob o viés da ordem social, ela se funda no primado do trabalho, o que significa dizer que a concretização de uma ordem social justa e solidária pressupõe que se busque por completo o trabalho, tanto pelos poderes constituídos, como também pela sociedade (mas também, e principalmente, pela sociedade (FINATI, 1996, p. 28). De forma resumida, a valorização constitucional dada ao trabalho no texto da Carta Magna significa tanto que deve ser valorizado o trabalho, como que deve ser desvalorizado o não-trabalho (CAMARGO, 1998, p. 44).

Por essa razão, não se pode aceitar como válido o argumento, segundo o qual tentar conduzir os beneficiários do Programa em questão contraria as suas diretrizes básicas, já que foi criado com a única e específica finalidade retirar as pessoas de condições miseráveis. Tal argumento deve ser totalmente rechaçado, mormente quando se analisa que mais de uma década já se passou e que a proposta originária de tal benefício foi eficientemente alcançada, sendo, portanto, imperioso pensa-lo para o amanhã, a fim de fazer a esse contingente de pessoas, que hoje não são mais miseráveis, que é possível chegar mais longe, em um lugar onde a ameaça da pobreza e da marginalização estejam verdadeiramente afastadas e essas pessoas realmente incluídas socialmente (SCHMIDT; RIBEIRO, 2015, p. 23).

Não basta, apenas, garantir que tais pessoas não serão mais miseráveis. Impende garantir que elas poderão ascender socialmente. A construção de uma sociedade fraterna, justa, livre e solidária depende da garantia de mobilidade social para os seus membros, o que demanda uma superação da visão assistencialista para uma de empoderamento social.

Corroborando com esse entendimento, convém trazer à discussão o pensamento de Sen (2012, p. 77), que diz:

\footnotetext{
"Os fins e os meios do desenvolvimento exigem que a perspectiva da liberdade seja colocada no centro do palco. Nessa perspectiva, as pessoas têm de ser vistas como ativamente envolvidas - dada à oportunidade - na conformação de seu próprio destino, e não apenas como beneficiárias passivas dos frutos engenhosos dos programas de desenvolvimento. O Estado e a sociedade têm amplos papéis no fortalecimento e na proteção das capacidades humanas. São papéis de sustentação, e não de entrega sob encomenda."
}

Essa nova perspectiva requer de forma prática a inclusão de uma nova condicionalidade no texto do art. $3^{\circ}$, da Lei $\mathrm{n}^{\mathrm{o}} 10.836 / 2004$, que, ademais de conferir ao Programa uma nova fase, também lhe outorgaria maior legitimação social, visto que essa nova fase requer uma articulação de setores da sociedade civil que criticam a sua formatação atual, 
porque entendem, na conformação atual, não é capaz de, sozinho, promover desenvolvimento humano e social, pelo que urge o seu aperfeiçoamento, a fim de que haja um real reconhecimento social, bem como uma garantia de liberdade, através da possibilidade de mobilidade social, de uma considerável parcela da população brasileira, que, anteriormente, engrossava a fileira dos completamente excluídos e marginalizados desse país.

Essas pessoas, retiradas da zona de pobreza, não podem, todavia, estar fadadas a permanecer definitivamente em uma condição social, capaz de apenas lhe conferir o mínimo necessário. Se as políticas públicas governamentais as retiram da zona de pobreza, deve lhes ser dada oportunidades para que elas, partindo das suas capacidades, possam ser reconhecidas socialmente, através do seu trabalho em qualquer uma de suas formas.

Desse modo, a fim de que os indivíduos sejam efetivamente autores das mudanças sociais, e não apenas expectadores, urge a preocupação do Estado em criar e efetivar políticas públicas que ampliam as liberdades e as oportunidades dos indivíduos, de modo que haja igual possibilidade de participação entre todas as pessoas.

\section{CONSIDERAÇÕES FINAIS}

Observa-se que, há muitas décadas o Brasil tem investido no setor social ainda que durante muito tempo de maneira fragmentada e sem controle dos resultados. A Constituição brasileira de 1988 tratou da assistência social tendo como ponto de partida o indivíduo, pelo que se entende que não se cumpre a dignidade da pessoa humana, preconizada no texto constitucional como princípio vetor do Estado Democrático de Direito brasileiro, apenas com políticas assistencialista.

Ao contrário, é necessário assistir o individuo com a finalidade de poder incluí-lo socialmente e, para tanto, mister retirá-lo da zona de pobreza ou de pobreza extrema. Nesse contexto, o Bolsa Família representa o programa social de maior abrangência já implantado no país e com maior possibilidade de promover a inclusão social por estar vinculado ao cumprimento de condicionalidades que levam ao exercício de direitos fundamentais mínimos, como saúde e educação. 
No entanto, seu maior desafio é precisamente a construção de um modelo de gestão de condicionalidades eficiente onde a capacitação para o trabalho adquira um papel mais central. Retirar as pessoas da pobreza ou da pobreza extrema foi um dos grandes passos dados na última década para minimizar a grande desigualdade de renda existente no País. Todavia, tal medida, conseguida através do Programa em questão, não pode ser visualizada como um fim em si mesmo.

O Programa Bolsa Família cumpriu o fim proposto, mas é imperioso avançar, porque não está na zona de pobreza é um dos passos para a real inserção social. Todavia, não é o único. Impende que esse indivíduo que antes se encontrava em situação de pobreza extrema tenha oportunidade de se desenvolver enquanto ser humano, enquanto pessoa dotada de aptidões e capacidades. O desenvolvimento dessas aptidões e capacidades precisam ser também fomentadas pelo próprio Programa, por meio da inserção de uma condicionalidade que verse sobre a capacitação para o trabalho ou empreendedorismo, já que o trabalho assume a conformação constitucional de valor social, o que impõe que o mesmo seja buscado tanto pelo particular, quanto pelas políticas públicas.

Essa inserção através do trabalho contribuirá para que um número expressivo de indivíduos saia do Programa por haverem alcançado a emancipação sustentável e a cidadania plena. Afinal de contas o êxito de um programa dessa natureza se avalia pelo número de indivíduos que deixam de ser dele beneficiários, porque passam a ter condições reais de proverem a sua manutenção econômica com a sua própria força laborativa. Nisso consiste a emancipação econômica e o empoderamento real dos beneficiários do Programa. É mister que o Programa Bolsa Família exitoso na sua conformação inicial, seja, nesse ponto, pensado para inclusão de nova fase, capaz de permitir a real emancipação econômica dos seus beneficiários.

Assim, é necessário avaliar a possibilidade de criação de uma nova fase no Programa, que seja capaz de garantir o efetivo acesso dos seus beneficiários a uma condição plena de emancipação econômica que tenha em conta a realização do trabalho, em primeiro lugar, através de capacitação, de formação e de políticas públicas e parcerias com entidades privadas que incentivem o trabalho e o empreendedorismo. 


\section{REFERÊNCIAS}

CAMARGO, Ricardo Antônio Lucas. A valorização do trabalho como componente do conceito de justiça social na constituição brasileira de 1988 e na constituição gaúcha de 1989 alguns aspectos inexplorados. Jornal Trabalhista, São Paulo: Consulex, v. 15, n. 692, p. 41-46, 1998.

CAMPELLO, Tereza. Uma década derrubando mitos e superando expectativas. In: CAMPELlO, Tereza; NERI, Marcelo Côrtes (Orgs). Programa Bolsa Família: uma década de inclusão e cidadania. Brasília: Ipea, 2013. p. 15-25.

CARVALHO, Maria do Carmo B. A política de assistência social no Brasil: dilemas na conquista de sua legitimidade. Serviço Social e Sociedade. São Paulo, ano XXI (março 2000), n. 62, p 144-155.

CASTEL, Robert. A Dinâmica dos processos de marginalização: da vulnerabilidade a “desfiliação”. CADERNO CRH, Salvador, n. 26/27, jan./dez., p. 19-40, 1997.

CASTRO, Jorge Abrahão de Castro; MODESTO, Lúcia (Org.). Bolsa Família 2003-2010: avanços e desafios. vol. 1. Brasília: IPEA, 2010.

ESCOREL, Sarah. Dicionário da Educação Profissional em Saúde. Rio de Janeiro: Fundação Oswaldo Cruz./Escola Politécnica de Saúde Joaquim Venâncio, 2009.

FIGUEIREDO, Maria do Amparo Caetano de. Inclusão Educacional na Exclusão: Políticas de Renda Mínima. (Tese de Doutorado em Educação). João Pessoa: Universidade Federal da Paraíba, 2008. Disponível em: http://www.capes.gov.br/. Acesso em 01/10/2010.

FINATI, Cláudio Roberto. O valor social do trabalho. Revista do Tribunal Regional do Trabalho da 15 ${ }^{\text {a }}$ Região, São Paulo: LTr, n. 8, p.. 28-39, 1996.

HENNIG SILVA, Andressa; FOSSÁ, Maria Ivete Trevisan: Analise de conteúdo: Exemplo de Aplicação da Técnica para Análise de Dados Qualitativos. Disponível em: <www.anpad.org.br>. Acesso em: 16 fev. 2015. 
LAVINAS, Lena; VARSANO, Ricardo. Programas de garantia de renda mínima e ação coordenada de combate à pobreza. Brasília: IPEA, 1997. Disponível em: <www.unisc.br.portal.upload.com. arquivo.programas.pdf>. Acesso em: 20.02.2015.

LENOIR, René. Les exclus: un français sur dix. Paris: Seuil, 1974.

MOBILIZADORES SOCIAIS. Combate à pobreza no Brasil: Conquistas e desafios. Oficina do Eixo Erradicação da Miséria. Laboratório Herbert de Souza Tecnologia e cidadania. Abril 2014. Disponível em: <http://mobilizadores.org.br>. Acesso em: 09 set. 2015.

MONNERAT, Giselle Lavina; SENNA, Mônica de Castro Maia; SCHOTTZ, Vanessa; MAGALHÃES, Rosana; BURLABDY, Luciene. Do direito incondicional à condicionalidade do direito: as contrapartidas do Programa Bolsa Família. Revista Ciência e Saúde coletiva. Rio de Janeiro, v. 12, n.6, pp.1453-1462, 2007.

MORA, Jose-Ferrater. Dicionário de Filosofia. São Paulo. Edicões Loyola, 2004.

PIZZIO, Alex; VERONESE, Marília. Veríssimo. Possibilidades conceituais da sociologia das ausências em contextos de desqualificação social. Cadernos de Psicologia Social do Trabalho, v. 11, n. 1, p. 51-67, 2008.

RODRIGUES, Cláudia. A (Des)valorização do trabalho humano pela Justiça do Trabalho.Jornal Trabalhista, São Paulo: Consulex, v. 20, n. 961, p. 12-13, 2003. p. 12.)

SALES, Tainah Simões. Análise da Lei $n^{0}$ 10.836/04 (programa bolsa família): o direito como promotor de mudanças sociais? Disponível em: <.http://www.publicadireito.com.br/artigos/?cod=f8580959e35cb093>. Acesso em: 10.04.2016.

SCHMIDT, Albano Franscisco; RIBEIRO, Marcia Carla Pereira. O Programa Bolsa Família: reavaliando as condicionantes de recebimento. In: BEDIN, Gilmar Antônio; CITTADINO, Gisele Guimarães; ARAÚJO, Florivaldo Dutra de. Poder, cidadania e desenvolvimento no Estado Democrático de Direito. Florianópolis: Conpedi, 2015, p. 148-174.

SEN, Amartya K. Desenvolvimento como liberdade. São Paulo: Companhia de Bolso, 2012. 
SILVER, Hilary. Social: Exclusion and social solidarity. Three paradigms. International labour Review, v. 133, p. 531-578, 1994.

SUPLICY, Eduardo Matarazzo. Renda de cidadania: a saída é a porta. 2 ed. São Paulo: Cortez, 2002.

WETZEL, Débora. Bolsa família e a redução silenciosa no Brasil. The World Bank. 2013. Disponível em: <http://www.worldbank.org/pt/news/opinion/2013/11/04/bolsa-familia- Brazilquiet-revolution>. Acesso em 25 jul. 